\title{
Redução de erros de medicação na enfermaria cirúrgica de um Hospital da região Central Serrana do ES.
}

\author{
Monica de Mônico Magalhães, Eliana Marianelli Martinelli, Andre Zani, Paola \\ Nascimento Brommerschenkel \\ Hospital Madre Regina Protmann (ACSC), Santa Teresa-ES, Brasil
}

Salus Vitae

ACSC Erros envolvendo medicações são frequentes em hospitais e são potencialmente preveníveis, ao contrário das reações adversas. No Brasil, Rosa, M.B estudou 4026 prescrições (7148 itens) em um hospital de referência de Minas Gerais, encontrando 3177 discrepâncias (44,45\%). No nosso levantamento de série histórica do projeto, coleta de dados entre janeiro e março de 2018, a revisão dos prontuários cirúrgicos revelou uma taxa de discrepância de medicação ( prescrição+ administração+ dispensação) da ordem de 51,2\% em média, com uma mediana de 56,8\%. O gasto bruto potencial estimado para o ano anterior ao projeto de melhoria foi da ordem de $\mathbf{R} \mathbf{\$} \mathbf{6 0 8 . 1 5 2 , 3 2 .}$

\section{Objetivo e Metodologia}

Para reduzir a taxa global de erros de medicação nos pacientes internados para cirurgia eletiva e urgência do Hospital Madre Regina Protmann de 56,8 \% para 15\% entre dezembro de 2017 e dezembro de 2018, um time composto de enfermeiros, farmacêuticos e médicos utilizaram as ferramentas qualitativas e quantitativas da Ciência da Melhoria para identificar, descrever e resolver problemas, através de ciclos de PDSAs e controle estatístico do processo (CEP). Os indicadores de resultados e processos escolhidos e sua definição foram baseados naqueles sugeridos no Protocolo de Segurança na Prescrição, Uso e Administração de Medicamentos do Programa Nacional de Segurança do Paciente (PNSP) do Ministério da Saúde (2013). A análise econômica do trabalho utilizou-se de uma modificação da ferramenta desenvolvida por Steve Rough (2012).

\section{Gráficos de Controle}

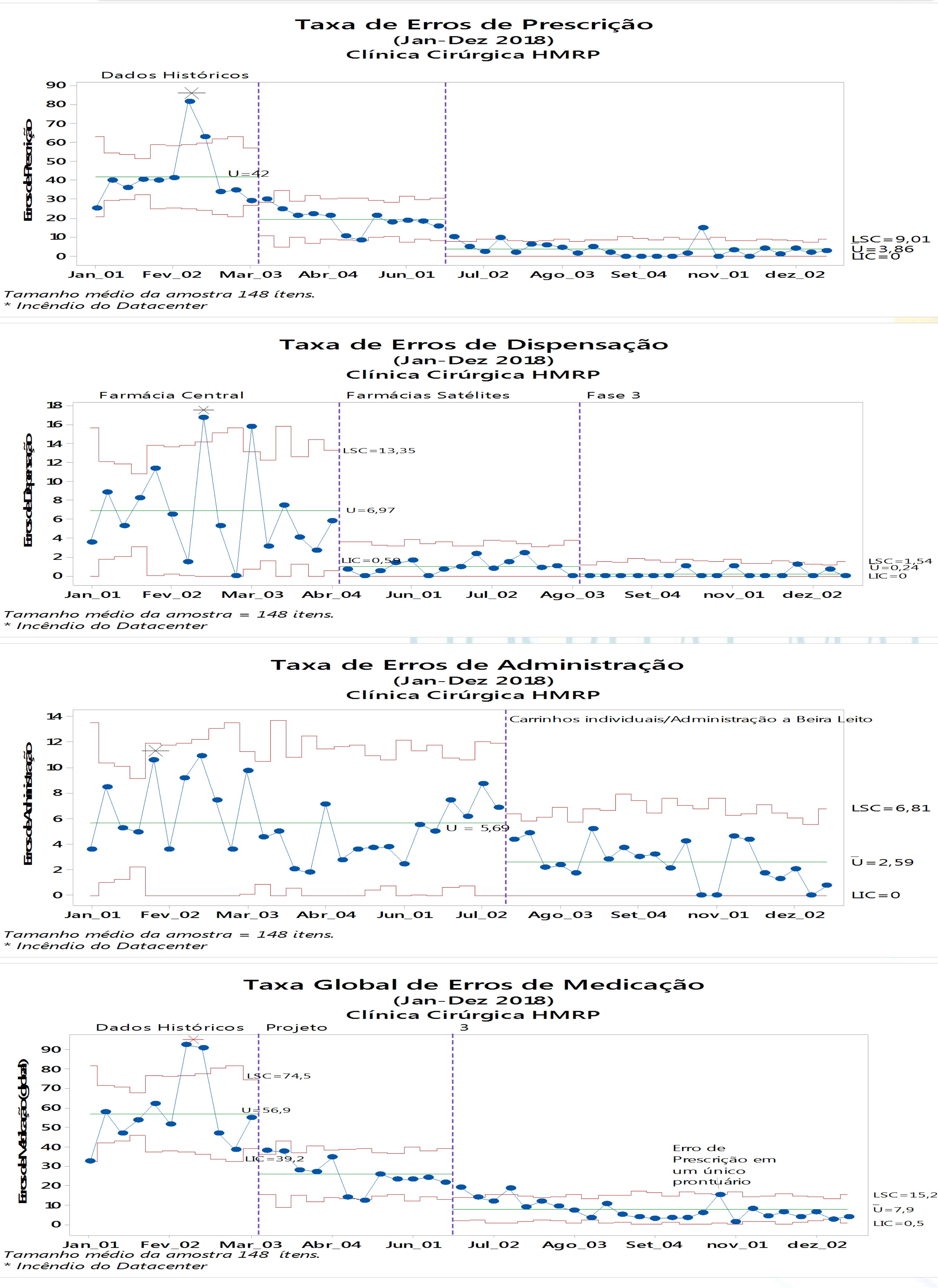

\section{Análise Econômica}

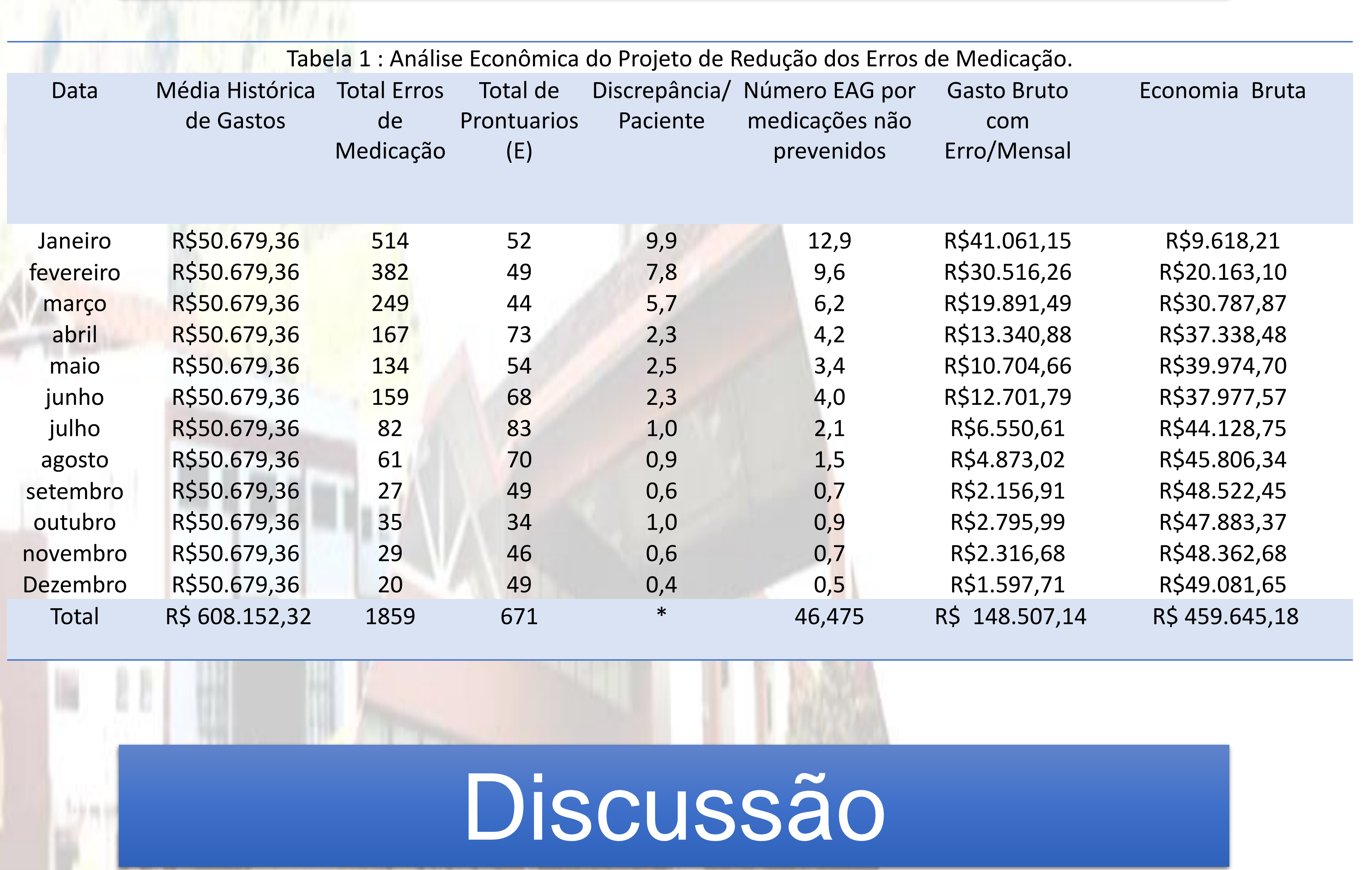

Os resultados mostraram uma efetiva redução na taxa de erros de prescrição, que saiu de uma mediana de $42 \%$ para 4,62\% (Gráfico 1) e dos erros de dispensação, que mostraram uma queda de $96,1 \%$ (Gráfico 2). A taxa de erros de administração foi a que teve menor resultado nos meses estudados, demonstrando uma queda de 56,1\% (Gráfico 3). De forma global, as medidas de melhoria adotadas pela equipe da enfermaria cirúrgica conseguiram diminuir em $86,1 \%$ a mediana da taxa global de erros (Gráfico 4). Quanto à análise econômica, considerando que o potencial de gasto do ano anterior foi de $R \$ 608.152,33$, e com a prevenção de aproximadamente 142 eventos adversos graves, a economia foi de $\mathrm{R} \$ 459.645,18$ até dezembro de 2018 (tabela I).

\section{Referências}

GLEASON, K. M. et al. Medications at Transitions and Clinical Handoffs (MATCH) toolkit for medication reconciliation. Prepared by the Island Peer Review Organization, Inc., under Contract No. HHSA2902009000 C, v. 13, 2011. Disponível https://www.ahrq.gov/sites/default/files/publications/files/match.pdf. Acesso em 13/03/2019.

MINISTÉRIO DA SAÚDE (BR). Protocolo de segurança na prescrição, uso e administração de medicamentos. 2013. Disponível https://www20.anvisa.gov.br/segurancadopaciente/index.php/publicacoes/item/seguranca-na-prescricao-uso-e-administracao-demedicamentos. Acesso em 13/03/2019.

PORTO, Silvia et al. A magnitude financeira dos eventos adversos em hospitais no Brasil. Rev Port Saúde Pública, v. 10, p. 74-80, 2010. ROSA, Mario Borges. Erros de medicação em um hospital de referência de Minas Gerais, 2001. 2002. Disponível http://www.bibliotecadigital.ufmg.br/dspace/handle/1843/AGPA-5L6F6B. Acesso em 13/03/2019. 